\title{
An RFID-based solution for monitoring sprayer movement in an orchard/vineyard
}

\author{
Changyuan Zhai ${ }^{1}$ (D) Andrew Landers ${ }^{2} \cdot$ Bo Zhang $^{1}$
}

Published online: 31 July 2017

(C) The Author(s) 2017. This article is an open access publication

\begin{abstract}
Pesticide application monitoring and long-term data recording in the field is typically the first step in fruit traceability. In a spray monitoring and guiding system, identification of the sprayer movement is a key part of technology. Although Global Navigation Satellite System (GNSS) is a widely used system to obtain location information, in an orchard/vineyard, especially one in which the trees/plants have tall and large canopies, the continuity and stability of the GNSS signal may decrease dramatically and lead to failure of guidance. A Radio Frequency Identification Devices (RFID) solution for identifying sprayer travel was proposed, and a spray monitoring and guiding system was designed based on this solution. In-lab system simulation test and field test results showed that the system could distinguish the travel direction of the sprayer, identify its location in the field, record flow rate information, calculate sprayed volume, and show all the above information on a computer screen in real-time when the RFID reader had successfully registered each RFID card. For the monitoring and guiding system with one antenna on each side, which required the cards and the antennas to be at the same height, the best relative position was found by placing the card parallel to the antenna. The results of tests in the field showed that an improved system with two antennas on each side, which only required the cards to be put in the band with a width of $0.26 \mathrm{~m}$ between the centers of the two antennas, worked better with the best antenna angle of $125^{\circ}$ when the speed of the sprayer was less than $1.8 \mathrm{~m} / \mathrm{s}$.
\end{abstract}

Changyuan Zhai

zhaichangyuan@nwsuaf.edu.cn

Andrew Landers

andrew.landers@cornell.edu

Bo Zhang

zhangbo_609@163.com

1 College of Mechanical and Electronic Engineering, Northwest A\&F University, Yangling 712100, People's Republic of China

2 New York State Agricultural Experiment Station, Cornell University, Geneva 14456, USA 
Keywords Movement identification - Travel direction · RFID · Spray monitoring · Orchard/vineyard sprayer

\section{Introduction}

Food traceability plays an increasingly important role in quality assurance to avoid potentially severe health hazards (Juraske et al. 2012; Pizzuti et al. 2014; Wilson and Otsuki 2004). It has become a legal requirement for participants at all tiers of the food supply chains in Europe and a voluntary business standard all over the world (Aung and Chang 2014; Schwägele 2005; Souza Monteiro and Caswell 2009). Currently, pesticides are widely used in fruit production in orchards and vineyards. The extensive use of pesticide and off-target spray (drift) may lead to public health and environmental problems (Gil et al. 2013; Jeon and Zhu 2012; Li et al. 2012; Poulsen et al. 2012). Pesticide application monitoring and the long-term documentation of its use in fields should be the first essential step in pursuing whole-chain traceability in the fruit industry.

During pesticide application in an orchard or a vineyard, the ends of the tree or vine rows are sometimes not wide enough for a sprayer to make a U-turn to the next adjacent row. In these circumstances, the operator often skips the row, sprays the next one, and plans to come back later (often referred to as alternate row or row skips). This requires him to memorize the spraying routes correctly, otherwise, over- or under- spraying may occur (Pontikakos et al. 2012). An orchard and vineyard spray monitoring and guiding system, which records the amount of pesticide applied and the route the sprayer travels, and then displays the data on a screen in real-time, can be of great assistance for the sprayer operator in order to improve their efficiency.

In the spray guiding system, identifying sprayer movement, including its location and direction of travel, plays a key role. The methods of sprayer movement identification have been studied recently. Sprayer position was often acquired using a GNSS for position estimation (Lee et al. 2010; Pérez-Ruiz et al. 2011). Pesticide application data and GNSS information were collected at the same time. A GIS map including location, time, and amount of the spraying application could be generated and displayed for the operator (Landers and Larzelere 2012). All the data could also be stored in a database on a computer (Landers and Larzelere 2012) or in an SD card (Reyes et al. 2012). This approach works well for an orchard or vineyard with relatively small plants and an open canopy where the GNSS position data is both continuous and stable. If plants are tall, dense, and with a large canopy, then the continuity, stability, and accuracy of the GNSS data may decrease dramatically (Ampatzidis et al. 2009) and lead to failure of guidance.

Many researchers apply RFID for location identification (Ko 2010; Ruiz-garcia and Lunadei 2011). RFID enables the identification of nearby objects or people by means of radio frequency (RF) signals (Hancke 2011; Peets et al. 2009; Vales-Alonso et al. 2011), and has become an indispensable technology in inventory tracking, object location, animal tracking, and environmental monitoring with the development of low-cost passive RFID tags (Awad 2016; Fan et al. 2013; Thakur and Forås 2015). Similar ideas could be adopted to monitor sprayer movement in an orchard or a vineyard. Low-cost RFID cards are mounted at the ends of each row. An RFID reader is installed on a sprayer with two antennas, one on the left side and one on the right side, which records the RFID card and its location while passing by during the spraying operation. In addition, the recording sequence of the cards and their locations will also provide information on travel direction which is critical for recording spraying operations. 
The objective of this paper is to explore an RFID-based solution for identifying orchard and vineyard sprayer movement, and to design a spray monitoring system to verify this solution.

\section{Materials and methods}

In order to automatically identify tractor movement and record real-time flow rate of a sprayer, a spray monitoring and guiding system was designed which consisted of an RFID detection system, a flow rate reading system, a computer software system, and a testing vehicle (Fig. 1). The RFID detection system was used to identify sprayer movement by detecting RFID cards mounted on poles at the ends of each tree or vine row. Two or four antennas were fixed on both front sides of the testing vehicle and faced the tree or vine rows. The RFID reader (ALR-9650 or ALR-9680, Alien Technology, Ltd., California, USA) read the RFID card information and sent it to an on-board computer through an RS232 serial port. The flow rate reading system included two Raven RFM 15 flow meters (Raven Industries, South Dakota, USA) which were used to measure the flow rates on both sides of the sprayer and a flow-rate recorder formed by a microcontroller, Arduino UNO ("Arduino-Home" n.d.). The flow-rate recorder sent the flow rate data to a computer through another RS232 serial port. After receiving RFID card information and flow rates, the computer identified sprayer movement, recorded the flow rate data in the database, and displayed the result on the computer screen.

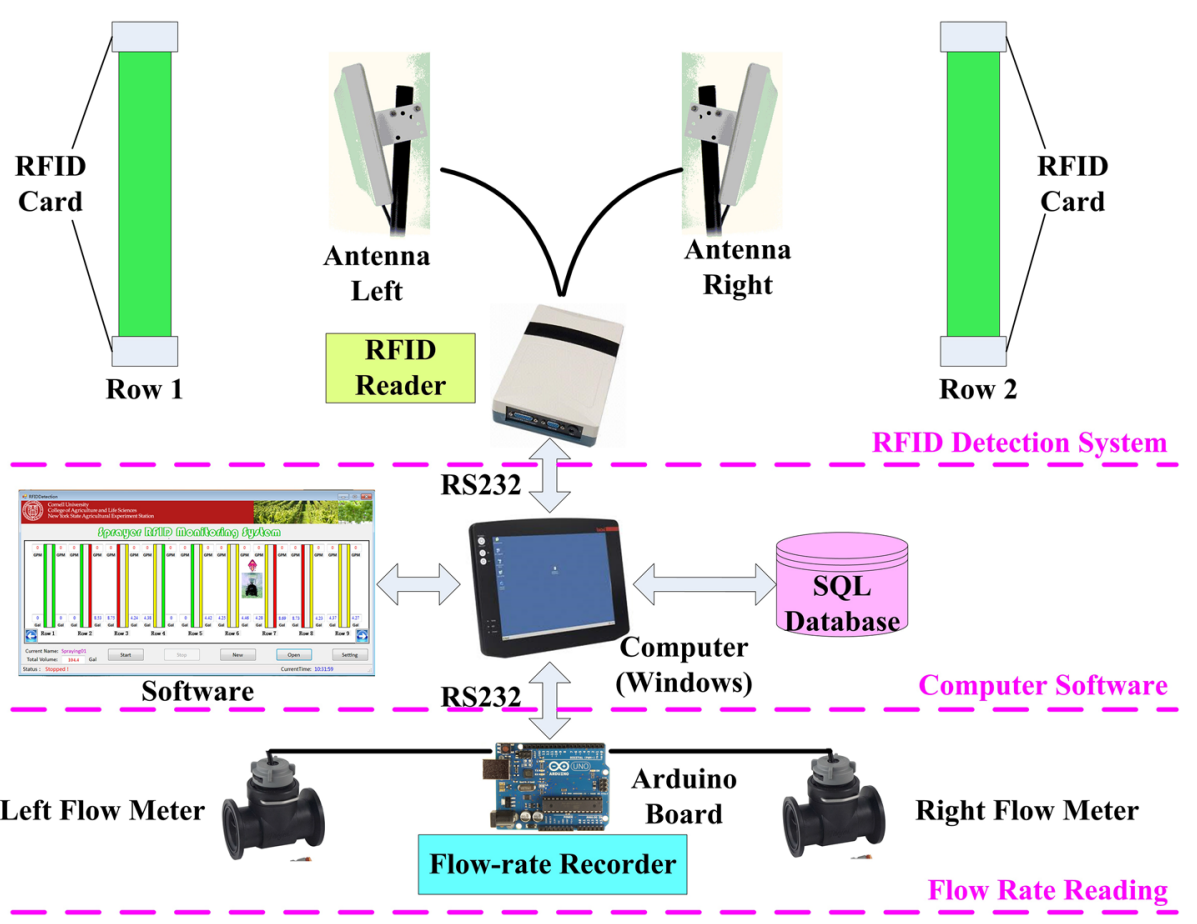

Fig. 1 Overview of the developed orchard/vineyard spray monitoring system 


\section{RFID system setup}

\section{RFID card arrangement in fields}

There were three types of tree or vine row in an orchard or a vineyard, i.e. an edge row, an internal row, and a single row (Fig. 2). The edge row was a start or an end row of a block in a field, which had only one adjacent row on its left or right side. The internal row had two adjacent rows at its sides, while the single row had no adjacent rows. The RF signal was affected by nearby metal materials and covered objects (Ruiz-garcia and Lunadei 2011). To minimize the influence, at the ends of each row, RFID cards were mounted on the wooden end posts which were outside of the tree or vine canopy.

The RFID card output comprised 24 characters, including a grower code (six characters), a farm code ( characters), a position percentage in a row (three characters), and a spare number (two characters). The position percentage was to show the card position in a tree or vine row. The position percentages of the cards mounted at the start and the end of a row were recorded as 0 and $100 \%$ respectively. The percentages of -1 and $101 \%$ marked positions $1 \%$ outside of each end. In each edge or internal row, two RFID cards with position percentages of 0 and $100 \%$ were installed, while in each single row four cards were installed at the position percentages of $-1,0,100$ and $101 \%$.

Assuming a field was put in an $x-y$ co-ordinate with the row number increasing along the $x$ axis, in each row the RFID cards must be arranged with position percentages increasing along the $y$ axis (Fig. 2). The travel positive direction was defined as the card

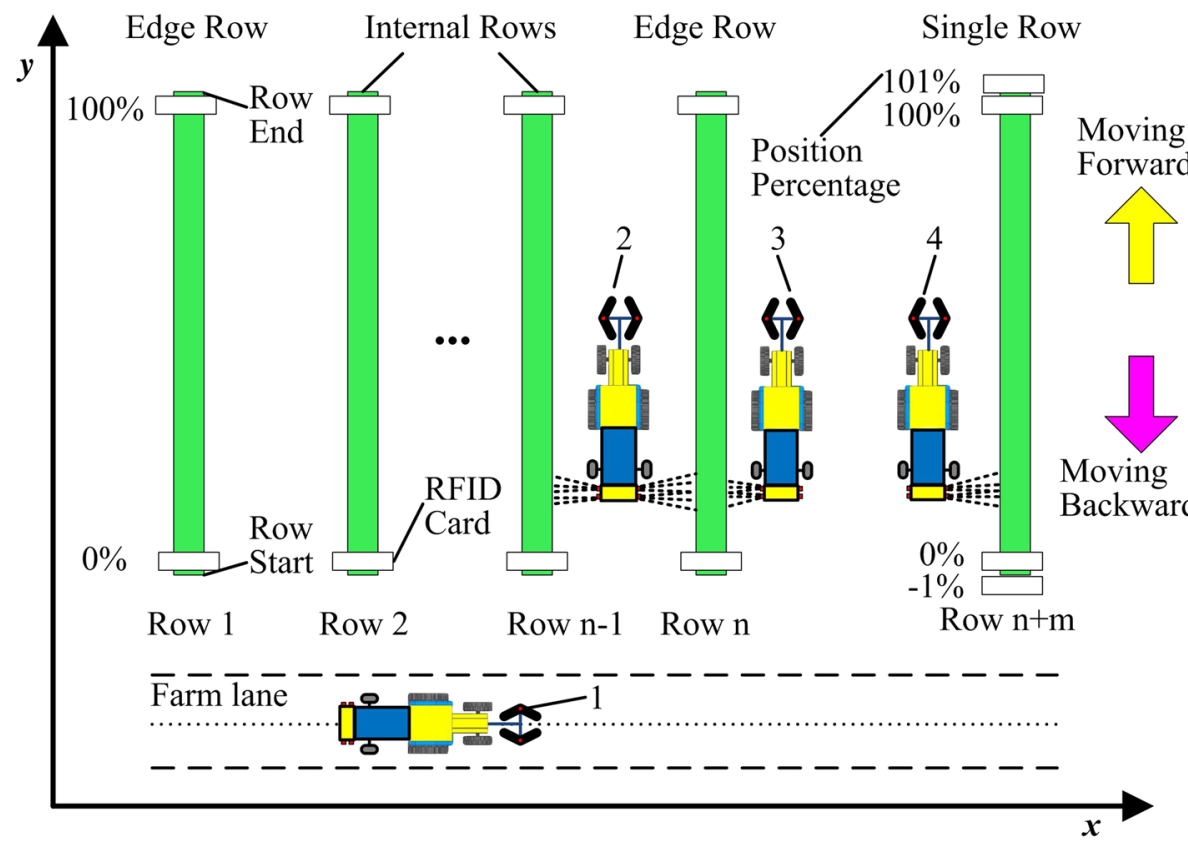

Fig. 2 The card arrangement in an orchard or a vineyard field and the travel of a sprayer: 1. The sprayer was moving along a farm lane, 2 . The sprayer was working between two adjacent rows, 3 . The sprayer was working outside an edge row, and 4 . The sprayer was working around a single row 
position percentage increasing direction (positive y). Travelling in this direction signified "moving forward", travelling otherwise signified "moving backward".

\section{RFID detection systems setup on a testing vehicle}

Two similar RFID readers (ALR-9650 or ALR-9680, Alien Technology, Ltd., California, USA) in the same series from the same company were employed to setup RFID detection systems. Both RFID readers supported Electronic Product Code Generation-2 (EPC Gen2) air interface protocol and International Organization for Standardization (ISO) 18,000-6c protocol in the Ultra High Frequency (UHF) range of 902.75-927.25 MHz. Their output was up to one watt of radio frequency power at each antenna. The output power could be raised by increasing the reader Power Radio Frequency Level (Power RFLevel), which could be set in the range of $17-29 \mathrm{dBm}$. The readers were powered with a 100-250 VAC power supply and communicated with the computer through an RS232 serial port. The RFID reader (ALR-9650) combined a reader and a circular polarized antenna, which supported another external antenna (ALR-8696-C, Alien Technology, Ltd., California, USA), while the RFID reader (ALR-9680) with no antennas inside possessed four channels for four external antennas (ALR-8696-C).

An RFID detection system with two antennas was setup using an ALR-9650 reader and an external antenna. The two internal and external antennas were fixed on two PVC pipes to the front of the testing vehicle, parallel to the tractor frame (Fig. 3).

An improved system was also setup using an ALR-9680 reader and four antennas (Fig. 4). On each side, two antennas were fixed at different heights and different directions. The height difference between the centers of the two antennas was $0.26 \mathrm{~m}$. Compared to the system with two antennas, this detection system should increase the detection scope and make card capture more likely.

\section{Sprayer movement and identification method}

When a sprayer was moving in an orchard or a vineyard field, it had four types of travel (Table 1). If a sprayer was moving along a farm lane between blocks it would not spray to either side (Type 1 in Fig. 2); it would spray to both sides when working between two adjacent

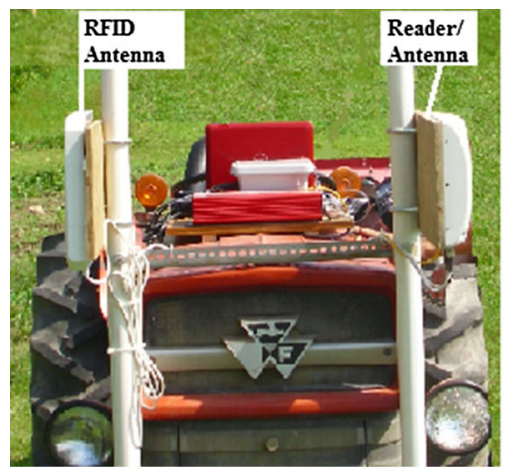

(a)



(b)

Fig. 3 The RFID detection system with two antennas on both sides: a Front view of the antennas fixed on the testing vehicle; b Left side view of the RFID detection system 


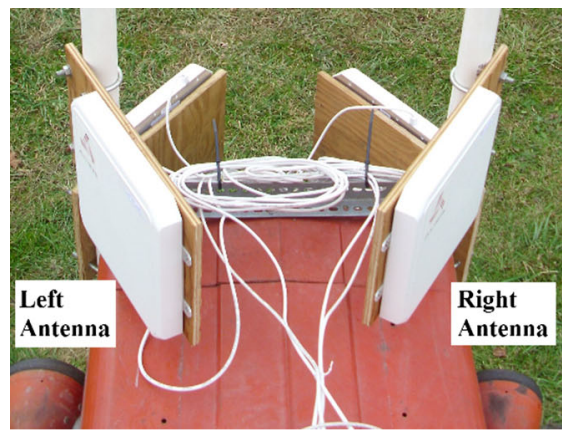

(a)

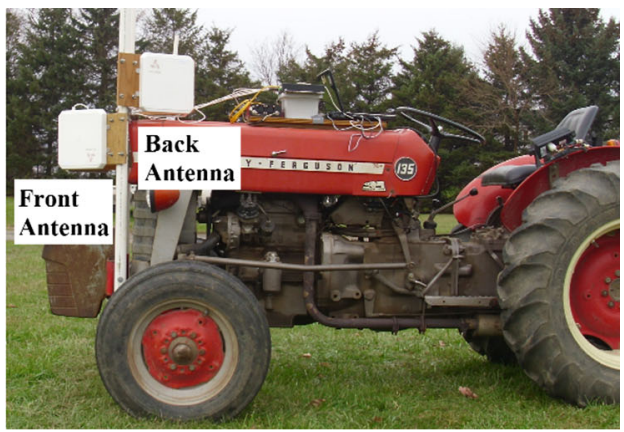

(b)

Fig. 4 The improved RFID detection system with four antennas on both sides: a Top view of the four antennas fixed on the testing vehicle; b Left side view of the improved monitoring and guiding system

Table 1 RFID reading direction and spray operation at different types of movements of a sprayer

\begin{tabular}{lll}
\hline Type of movement & RFID reading direction & Spray operation \\
\hline Type 1. Moving along a farm lane & None & No spraying \\
Type 2. Moving on adjacent rows & Reading both sides & Spraying both side \\
Type 3. Moving along an edge row & Reading one side & Spraying one side \\
Type 4. Moving around a single row & Reading one side & Spraying one side \\
\hline
\end{tabular}

rows (Type 2 in Fig. 2). When it was working outside an edge row or around a single row, it would spray to only one side, towards the tree/vine row (Type 3 and 4 in Fig. 2).

A sprayer movement identification algorithm was developed to find the location and the direction of travel of the sprayer (Fig. 5). After the spray monitoring and guiding system started, the on-board computer sent request commands to the RFID reader to search for nearby RFID cards. If a registered RFID card was found, the card information was read and analyzed to query whether the same card was read previously. If not, the RFID card information was stored into the database. Otherwise, the card information was discarded. Then the flowmeters on both left and right sides would be read to know which side or sides were being sprayed. The sprayer movement would be identified using an algorithm based on card signals from both sides or one side. The system would run continuously until stopped by the user.

\section{Sprayer movement identification from both sides}

When a sprayer sprayed to both the left and right sides, the system would read RFID cards from both sides at the end of each row. If the cards were from two adjacent rows, the current row number of the sprayer was the maximum number of both cards. When the position percentages of both cards were 0 , the sprayer position was at the start of a row. Under this circumstance, if the previous row number recorded was equal to the current row number, the sprayer was moving backward, otherwise it was moving forward. Similarly, when the position percentages were $100 \%$, the sprayer was at the end of a row; and if the previous row number equaled the current row number, the sprayer was moving forward, otherwise it was moving backward (Fig. 6). 


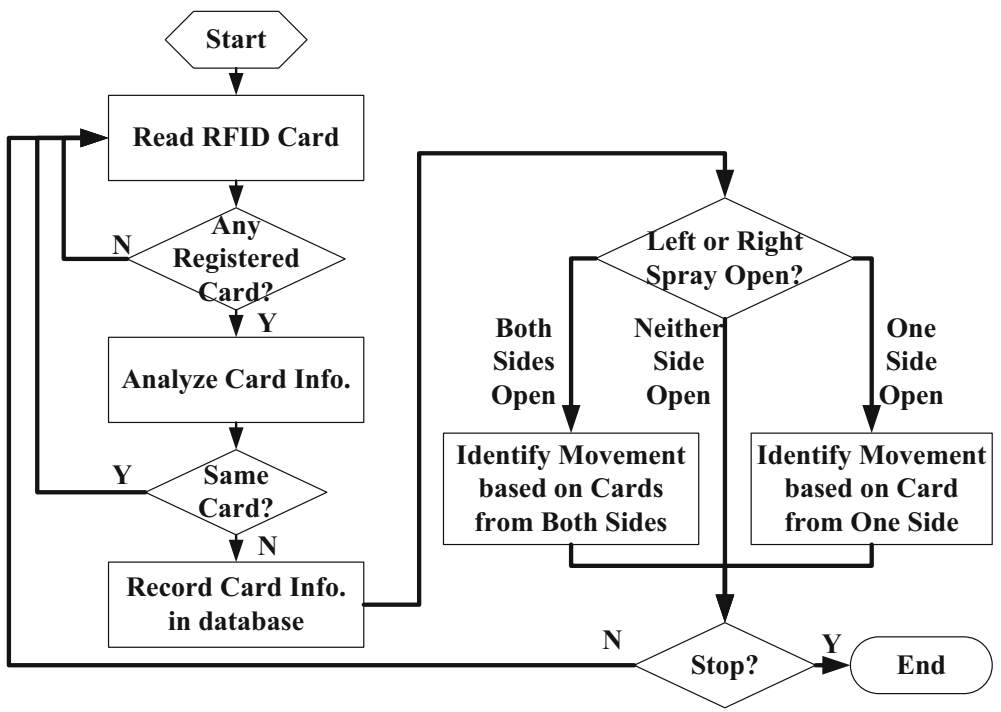

Fig. 5 Flow chart of sprayer movement identification algorithm

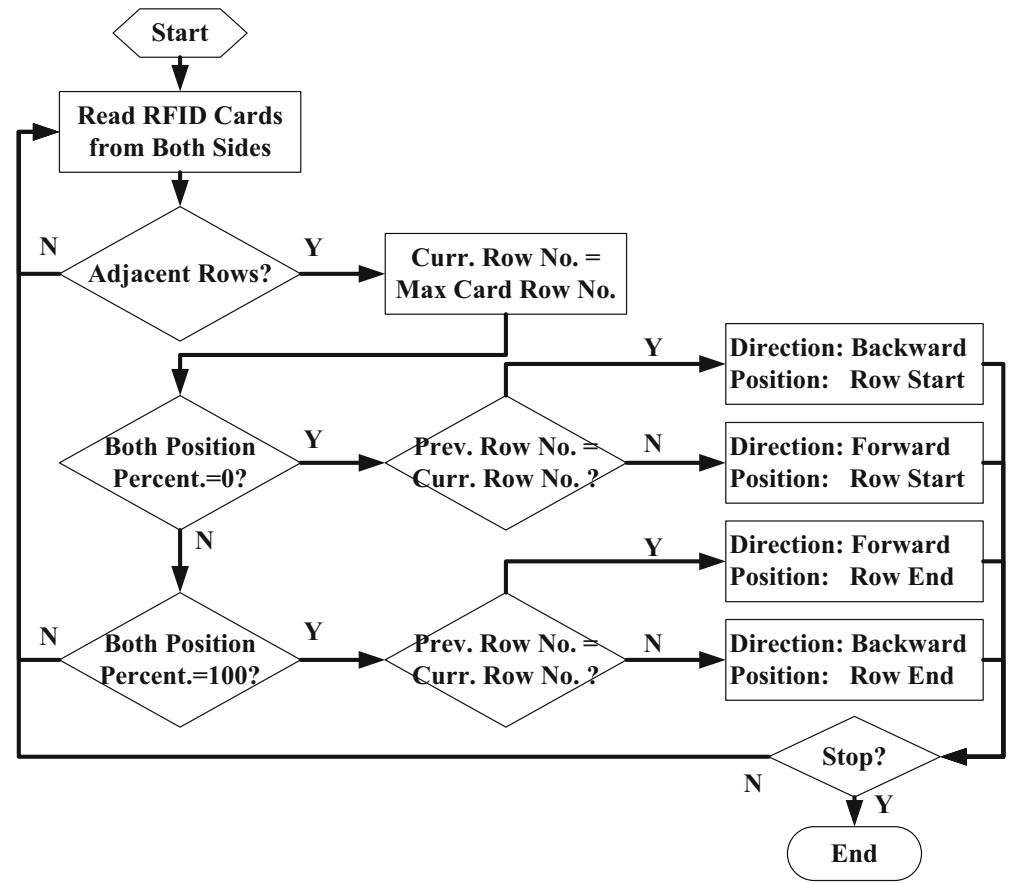

Fig. 6 Algorithm flow chart of sprayer movement identification from both sides 


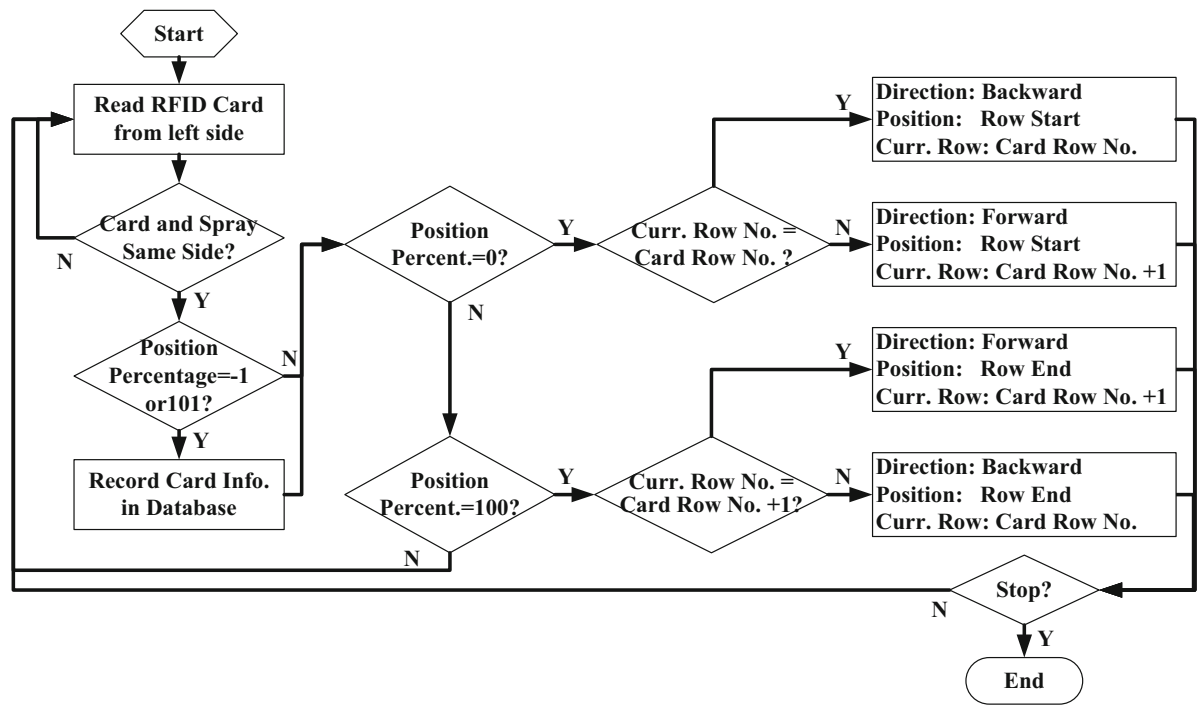

Fig. 7 Algorithm flow chart of sprayer movement identification from left side

\section{Sprayer movement identification from one side}

If a sprayer was working outside an edge row or around a single row, it would spray to only one side. The system read the RFID cards from that side. The RFID card information was discarded if they were not from the same side as the spraying direction. Then the cards reserved information would be analyzed. Take sprayer movement identification from the left side for example. If the position percentage of a card was -1 or $101 \%$, which was placed in a single row, the card information would be recorded in the computer database. When the position percentage was 0 , the sprayer was at the start of a row; and if the current row number equalled the card row number, the sprayer was moving backward with its row number the same as the card row number. Otherwise the current row number of the sprayer was the card row number +1 with forward direction of travel. Similarly, if the position percentages were $100 \%$, the sprayer was at the end of a row. On this occasion, if the current row number was the same as the card row number +1 , the moving direction was forward and the current row number was card row number +1 . Otherwise the direction of travel was backward and the current row number was the same as card row number (Fig. 7).

\section{Design and development of the computer system software}

The computer system software was designed and developed to run under Microsoft Windows operating system using C\# language based on Microsoft Visual Studio 2012. The software identified the sprayer position and travel direction based on the movement identification algorithm shown in Fig. 5. If the sprayer was moving backward at the start of a row or moving forward at the end of a row, the software would update the row number where the sprayer was located, then start to display the flow rate in real time, show the sprayer position and direction on the screen, and record the start time into the database for spray application records. Otherwise, if the sprayer was moving forward at the start of a 


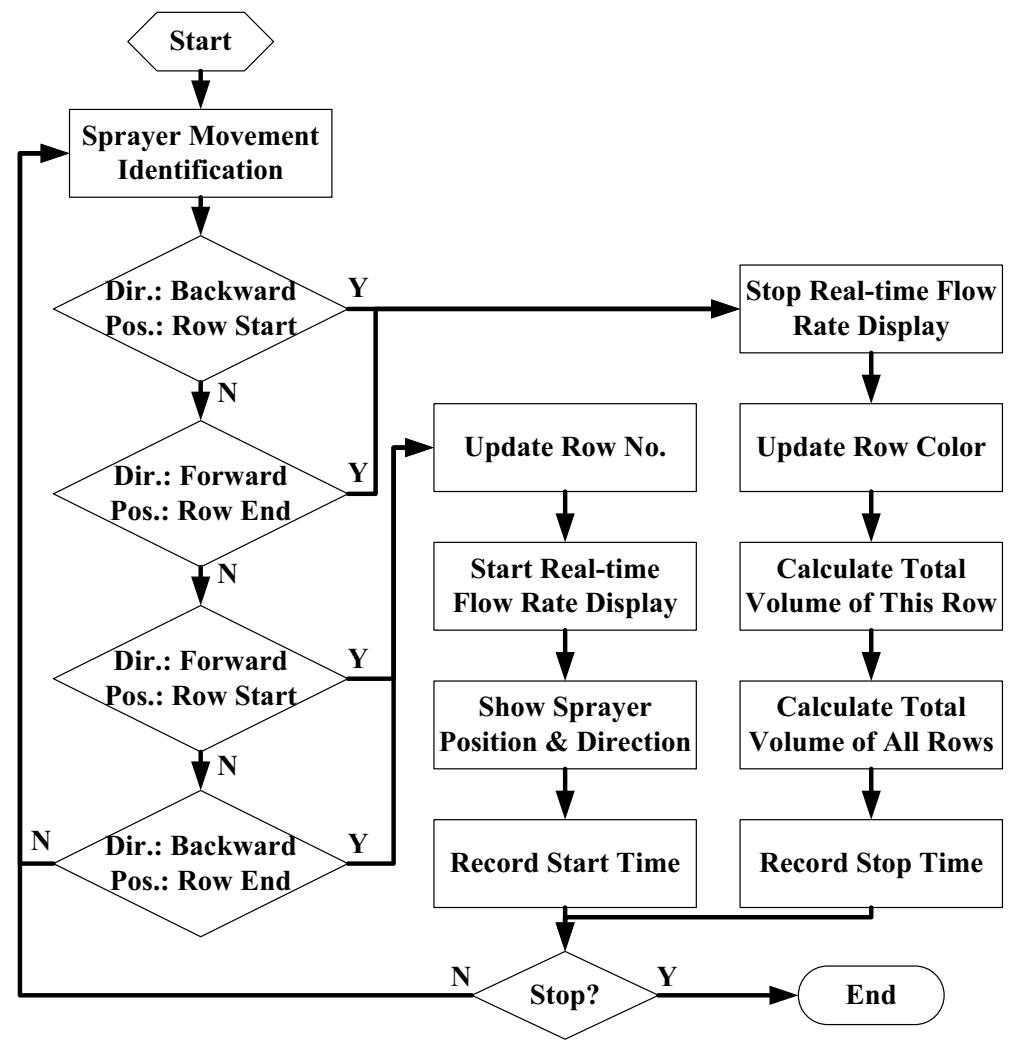

Fig. 8 Flow chart of movement identification and guiding module

row or moving backward at the end of a row, the software would stop the real-time flow rate displaying, and update the row color according to the number of spraying times (Green: never sprayed, Yellow: sprayed once, and Red: sprayed twice or more); then the software would search all the flow rate records from the database based on the start and stop time for this row, multiply each flow rate value and its time interval, sum all the multiple results up to calculate the total volume of this row, and add together the volumes applied to all the sprayed rows to calculate the total spraying volume in the field; finally the software would record the stop time into the database for the row spraying, and show the volume results on the screen in real-time (Fig. 8).

\section{Development of the flow-rate recorder}

The flow-rate recorder was developed using an Arduino board, which was used to read the information from the two flow meters and sent the result to the computer (Fig. 9). The serial port string format was set as "\$side:****GPM" in which the "side" was "Left" or"Right" and the "****" was the flow rate data, i.e. "\$Left:1.52GPM". The string was sent out every second automatically to the computer.

The flow meter Raven RFM 15 (Raven Industries, South Dakota, USA) was powered by a $12 \mathrm{~V}$ battery. The output signal was a $12 \mathrm{~V}$ pulse train at a rate of 44.4 pulses/ 1 with a 


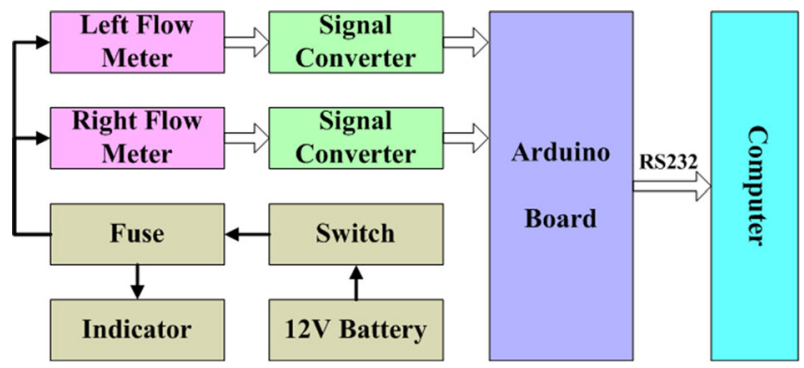

Fig. 9 Circuit schematic diagram of the flow-rate recorder

measurement range of $1.1-56.8 \mathrm{l} / \mathrm{min}$. The signal converter transformed the $12 \mathrm{~V}$ signal to the $5 \mathrm{~V}$ signal which could be accepted by the Arduino board.

\section{Experimental design}

\section{Flow-rate recorder precision test using simulative pulse signal}

In order to test the precision of the flow-rate recorder, a test system was developed using a PC oscilloscope (PicoScope 2205, Pico Technology, United Kingdom) which could generate precision pulse signals with different frequencies (Fig. 10). The maximum voltage of a pulse signal that the PC oscilloscope could generate was $2 \mathrm{~V}$. The Arduino board in the flow-rate recorder accepted a $5 \mathrm{~V}$ signal. A signal converter circuit was designed using an optocoupler chip (K817P2, Vishay Electronic GmbH, Germany) to convert a $2 \mathrm{~V}$ pulse signal to a $5 \mathrm{~V}$ pulse signal. The flow-rate recorder analyzed the $5 \mathrm{~V}$ pulse signal, calculated the pulse period, and sent the result to the computer frequently.

According to the flow rate range and calibration number of the Raven RFM 15 flow meter, the output signal frequency range of the flow meter could be calculated as $0.84-42 \mathrm{~Hz}$. In this frequency range, the precision of the flow-rate recorder was tested.

\section{Flow-rate recorder precision test using flow meter}

The flow-rate recorder flow rate precision test was conducted using a flow meter (Fig. 11). The flow meter was connected to a water pipe in which the water flow rate could be adjusted. The flow rate of water was regulated at different values. The flow rate was read using the flow-rate recorder, and was measured manually at the same time using a 5-gallon

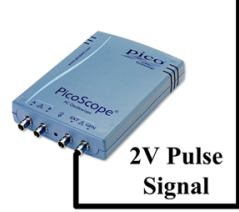

PC Oscilloscope

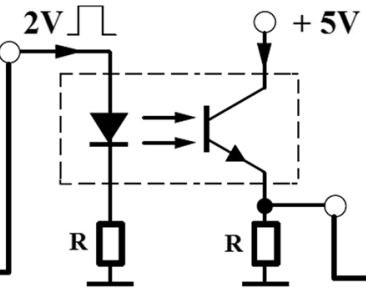

Signal Converter Circuit

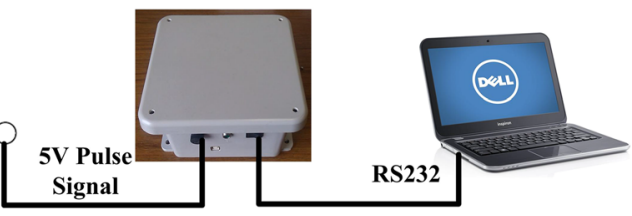

Flow-rate Recorder
Computer

Fig. 10 Flow-rate recorder precision test system using simulative pulse signal 


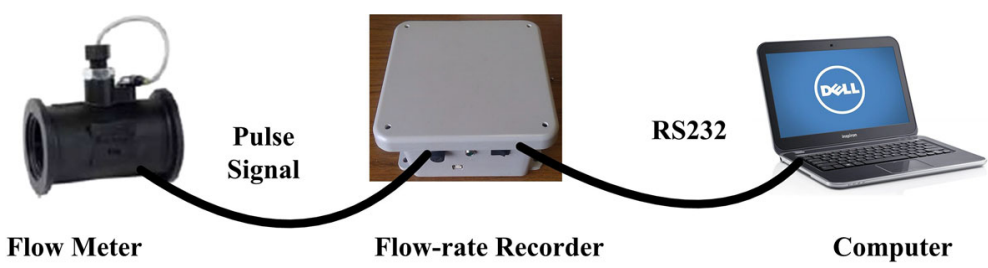

Fig. 11 Schematic diagram of flow-rate recorder precision test using flow meter

cylinder (18.93 1) and a stopwatch. At each measurement, the time for filling up the cylinder was obtained using the stopwatch.

\section{Tests on maximum command request frequency of the RFID reader}

In terms of mobile RFID detection, the more frequent the information request response was, the better the detection sensitivity would be. In order to measure the maximum available request frequency, request frequency tests for the RFID reader with two antennas (ALR-9650) and four antennas (ALR-9680) were conducted. The RFID reader was connected to the computer. The computer sent request commands periodically and received the responses using a serial debugging tool. The total delay time was recorded using a stopwatch after sending about 100 request commands.

\section{RFID detection distance test in the lab}

The RFID detection distance test was conducted to determine the best way of mounting the antennas on the sprayer and the installation of RFID cards on the orchard or vineyard rows. It was necessary to know the maximum detection distance when the antenna was parallel to the card (Fig. 12a). If the cards were fixed on the end of rows, when the sprayer took a U-turn, the card angle would change (Fig. 12b). When the sprayer went along the row, the antenna angle would change (Fig. 12c). To conduct the tests one antenna of the RFID detection system was fastened on a tripod. On the ground, a vertical line and five oblique lines were set from the plumb position of the antenna. Each angle between the adjacent lines was $15^{\circ}$. An RFID card was fixed on a vertical bar, mounted on a movable plank. An indicator stick was attached to the plank for easier measuring of the card angle. The card was slowly moved closer to the antenna. When the computer started reading the card continuously, the maximum distance, which was the detection distance, was measured. Three tests were carried out. In the first test (Fig. 12a), the RFID card paralleled the antenna surface, and the detection distances were measured three times and averaged out when the Power RFLevel was set from 17 to $29 \mathrm{dBm}$ with an increment of $3 \mathrm{dBm}$. In the second one (Fig. 12b), at different card angles, the detection distances were obtained separately while the Power RFLevel was set at $23 \mathrm{dBm}$. Similarly, in the third one, the detection distances were measured at different antenna angles while the Power RFLevel was also set at $23 \mathrm{dBm}$.

\section{RFID detection test at different moving speeds}

An RFID detection test was done when the sprayer moved at different speeds (Fig. 13). The two antennas were fixed to the front of the tractor $0.61 \mathrm{~m}$ apart. When the sprayer 



(a)

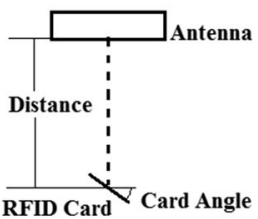

(b)

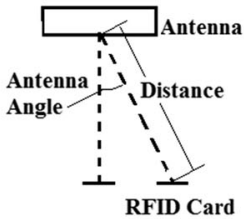

(c)

Fig. 12 RFID detection distance test in the lab. a The card was parallel to the antenna, $\mathbf{b}$ test with different card angles, $\mathbf{c}$ test with different antenna angles

Fig. 13 RFID detection test at different moving speeds

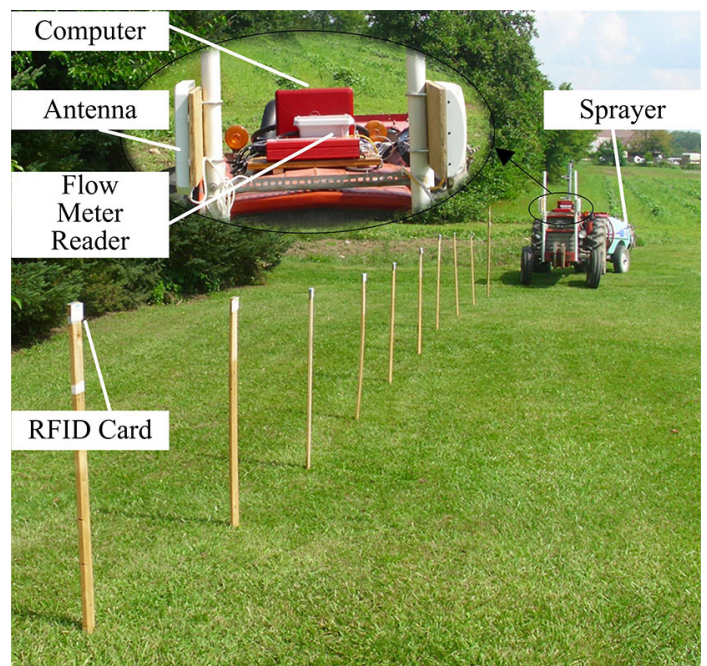

moved along the middle line of a vehicle lane in a field with a row width of $2.7 \mathrm{~m}$, the minimum distance from the antenna to a card in the nearest row was $1.05 \mathrm{~m}$, while it was $3.75 \mathrm{~m}$ to a card in the next row. Therefore, the RFID detection distance should be less than $3.75 \mathrm{~m}$; otherwise, the reader would register cards in the next row, which might lead to incorrect location identification. When the detection distance was less than $3.75 \mathrm{~m}$, the greater it was, the better the RFID system worked. The detection distances of some cards, 
which were tested on the vertical line of the reader, were measured when the Power RFLevel was set at $29 \mathrm{dBm}$. Ten of the cards whose detection distances were from 2.3 to $3.75 \mathrm{~m}$ were chosen. The ten cards were nailed on ten poles which were equidistant in a line on the ground. The length between the first and the last poles was $15 \mathrm{~m}$. The centers of the antennas and the cards were at the same height. The sprayer was driven along a line which was $1.4 \mathrm{~m}$ away from and parallel to the card line. The computer software recorded the card information read by the RFID reader. Note that the software would not read the card again if the card information had already been recorded.

In terms of spraying in an orchard or a vineyard, the speed of a sprayer was usually less than $1.5 \mathrm{~m} / \mathrm{s}$. During the tests for the left and right antennas, the gear of the tractor (MF135, Massey Ferguson, Georgia, USA) was set at "first low", "third low" and "first high". The real speed of the sprayer was measured and calculated using a stopwatch.

\section{Field test for the developed spray monitoring system with two RFID antennas}

A system simulation test and a field test were conducted. In the simulation test, a sprayer mounted with the monitoring and guiding system was stopped in an open field area. RFID cards were manually moved horizontally in front of the center of antennas to simulate the sprayer working in a field. All the four kinds of sprayer movements, which were moving along a farm lane, working between two adjacent rows, outside an edge row and round a single row, were simulated and tested.

The system was also tested in a vineyard (Fig. 14). The row width of the vineyard was $2.7 \mathrm{~m}$. At the beginning or end of each row, there was a pole outside of the vine canopy, on which an RFID card was fixed parallel to the row. When the sprayer went along the row, the antennas were parallel to the cards. The sprayer drove along three rows at the same speed, during which the RFID reader should register 12 RFID cards in total. The test was repeated four times. In the first repetition test, the RFID cards were put on the poles at similar heights without measuring them. In the second and third tests, the sprayer was set near one pole. The card on the pole and the antennas were adjusted to the same height. The



Fig. 14 RFID detection system test in the vineyard 
height of the card was measured from the ground near its pole. The other cards were also adjusted to the same height from the ground near their poles. At the last test, the sprayer was moved to each pole, and every card was regulated at the same height as the antennas.

\section{Field test for the improved spray monitoring system with four RFID antennas}

Before the system test, the RFID card detection distances were tested, and then ten cards were chosen with detection distances from 3.30 to $3.43 \mathrm{~m}$. In order to make the antennas on each side cover more scope, the antennas were fixed in different directions (Fig. 15). The greater the length of scope, the better the RFID detection system. The angle $\theta$ of the front and back antennas would affect the length of the scope. A test was done to find the best angle. One of the ten cards chosen was fixed on the orchard row positioned at the same line with the two poles (Point $\mathrm{A}$ in Fig. 15). The angle $\theta$ was made smaller and smaller from $180^{\circ}$ by rotating the back and front antennas at the same time. The minimum value of angle $\theta$ was the best angle when the card fixed at point " $\mathrm{A}$ " could be read continuously.

The improved RFID detection system with four antennas was tested in a vineyard. The ten cards chosen were fixed on a row in the vineyard with random heights between the centers of the lower and upper antennas. The speed of the sprayer was adjusted to 0.6, 1.1 and $1.8 \mathrm{~m} / \mathrm{s}$ by using the manual throttle based on GPS real-time data (GPS Magellan eXplorist 210, MiTAC Digital Corporation, California, USA), while the gear of the tractor was set at "first low", "third low" and "first high". When the sprayer moved along the row, the card information was recorded in the SQL Server database.

\section{Results and discussion}

\section{Flow-rate recorder precision test using simulative pulse signal}

The test results showed that the precision of the flow-rate recorder was very high with a maximum relative error of $0.50 \%$ (Table 2).

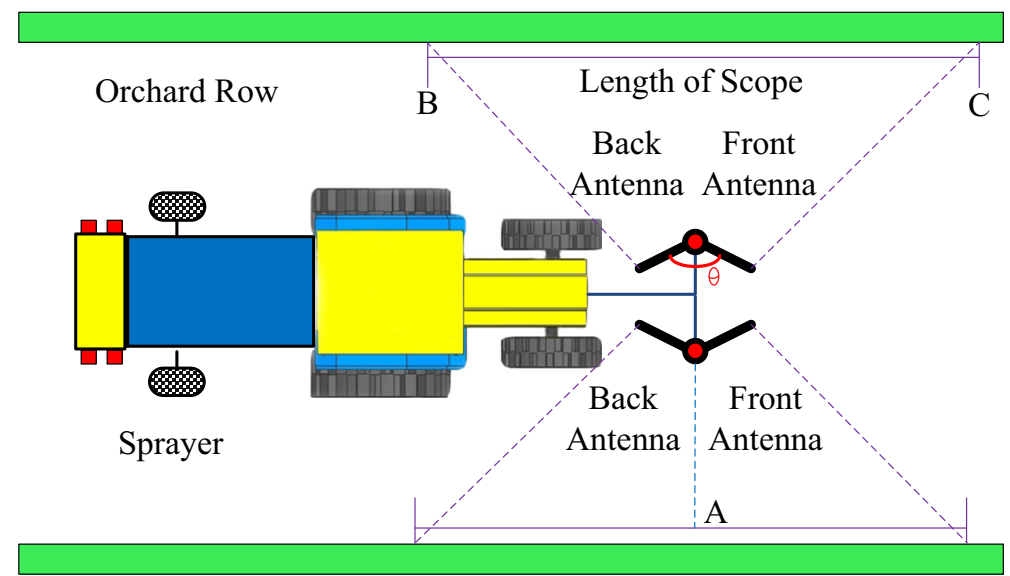

Fig. 15 Schematic diagram of test of the new RFID detection system with four antennas 
Table 2 Results of flow-rate recorder precision test using simulative pulse signal

\begin{tabular}{|c|c|c|c|c|c|c|}
\hline \multirow[t]{2}{*}{$\begin{array}{l}\text { Frequency of } \\
\text { simulative signal }(\mathrm{Hz})\end{array}$} & \multicolumn{4}{|c|}{$\begin{array}{l}\text { Pulse period calculated by the flow-rate recorder } \\
\text { (us) }\end{array}$} & \multirow[t]{2}{*}{$\begin{array}{l}\text { Frequency } \\
\text { calculated }(\mathrm{Hz})\end{array}$} & \multirow[t]{2}{*}{$\begin{array}{l}\text { Relative } \\
\text { error }(\%)\end{array}$} \\
\hline & 1 & 2 & 3 & Average & & \\
\hline 0.84 & 1187240 & 1187248 & 1187247 & 1187245 & 0.842 & 0.27 \\
\hline 5 & 199206 & 199199 & 199201 & 199202 & 5.020 & 0.40 \\
\hline 10 & 99599 & 99599 & 99605 & 99601 & 10.040 & 0.40 \\
\hline 20 & 49770 & 49770 & 49771 & 49770 & 20.092 & 0.46 \\
\hline 30 & 33177 & 33177 & 33179 & 33178 & 30.141 & 0.47 \\
\hline 40 & 24874 & 24873 & 24881 & 24876 & 40.199 & 0.50 \\
\hline 42 & 23688 & 23689 & 23703 & 23693 & 42.206 & 0.49 \\
\hline
\end{tabular}

\section{Flow-rate recorder flow rate precision test}

The flow rate precision test results showed that the maximum relative error was $4.32 \%$ when the flow rate range was $4-301 /$ min (Table 3 ).

\section{Tests on maximum command request frequency of the RFID readers}

The total delay time after sending about 100 request commands using the ALR-9650 RFID reader is listed in Table 4 . Time needed per request was calculated by adding the average delay time per request and the request command period. The maximum time needed per request was $0.350 \mathrm{~s}$ with an average of $0.345 \mathrm{~s}$. Therefore, the request command sending period was set as $0.35 \mathrm{~s}$ in the computer software.

The result of the test for the new RFID reader (ALR-9680) command request frequency using the same method as the previous RFID reader (ALR-9650) showed that the maximum time needed per request was $0.68 \mathrm{~s}$, which was almost double the time the ALR-9650 reader needed. One possible explanation is that the ALR-9680 reader needs to scan its four channels one by one to read cards nearby after receiving a command request, while the ALR-9650 reader only has two channels to scan.

Table 3 Results of flow-rate recorder flow rate precision test

\begin{tabular}{lccccccc}
\hline $\begin{array}{l}\text { Average flow rate from } \\
\text { flow-rate recorder (1/min) }\end{array}$ & \multicolumn{4}{l}{ Flow rate manually measured } & \multicolumn{2}{l}{$\begin{array}{l}\text { Relative } \\
\text { error }(\%)\end{array}$} \\
\cline { 2 - 8 } & 1st (s) & 2nd (s) & 3rd (s) & $\begin{array}{l}\text { Average } \\
\text { Time (s) }\end{array}$ & $\begin{array}{l}\text { Volume } \\
(1)\end{array}$ & $\begin{array}{l}\text { Flow rate } \\
(1 / \mathrm{min})\end{array}$ \\
\hline 3.73 & 290.4 & 291.2 & 291.2 & 290.93 & 18.93 & 3.90 & -4.32 \\
8.23 & 141.2 & 142.2 & 140.0 & 141.13 & 18.93 & 8.05 & 2.24 \\
10.95 & 104.9 & 105.5 & 105.0 & 105.13 & 18.93 & 10.80 & 1.40 \\
16.24 & 68.47 & 68.22 & 68.28 & 68.32 & 18.93 & 16.62 & -2.30 \\
22.97 & 49.00 & 48.72 & 49.56 & 49.09 & 18.93 & 23.13 & -0.67 \\
30.56 & 37.62 & 37.59 & 37.88 & 37.70 & 18.93 & 30.12 & 1.45 \\
\hline
\end{tabular}


Table 4 Result of request frequency test of the RFID reader (ALR-9650)

\begin{tabular}{|c|c|c|c|c|c|c|c|c|}
\hline \multirow{2}{*}{$\begin{array}{l}\text { Request } \\
\text { command } \\
\text { period (s) }\end{array}$} & \multicolumn{2}{|c|}{$1 \mathrm{st}$ test } & \multicolumn{2}{|c|}{2 nd test } & \multicolumn{2}{|c|}{ 3rd test } & \multirow{2}{*}{$\begin{array}{l}\text { Average delay } \\
\text { per request (s) }\end{array}$} & \multirow{2}{*}{$\begin{array}{l}\text { Time needed } \\
\text { per request }(s)\end{array}$} \\
\hline & $\begin{array}{l}\text { Total } \\
\text { delay } \\
\text { (s) }\end{array}$ & Times & $\begin{array}{l}\text { Total } \\
\text { delay } \\
(\mathrm{s})\end{array}$ & Times & $\begin{array}{l}\text { Total } \\
\text { delay } \\
\text { (s) }\end{array}$ & Times & & \\
\hline 0.1 & 24.7 & 101 & 25.1 & 103 & 25.3 & 103 & 0.245 & 0.345 \\
\hline 0.2 & 15 & 100 & 14.7 & 99 & 14.9 & 99 & 0.150 & 0.350 \\
\hline 0.3 & 4.3 & 101 & 3.8 & 100 & 3.6 & 99 & 0.039 & 0.339 \\
\hline 0.4 & 0 & 100 & 0 & 101 & 0 & 100 & 0 & $<0.4$ \\
\hline 0.5 & 0 & 101 & 0 & 100 & 0 & 100 & 0 & $<0.5$ \\
\hline
\end{tabular}

\section{RFID detection distance test in the lab}

Table 5 shows the detection distances when the Power RFLevel of the reader was set at different values from 17 to $29 \mathrm{dBm}$. The results showed that the higher the Power RFLevel, the greater the detection distance in which the reader would register the card. The Power RFLevel should be chosen according to the row width in the field. The results of RFID detection distances at different card angles showed that the detection distance decreased sharply when the card angle became larger (Table 6). The results of detection distances at different antenna angles showed that the greater the antenna angle, the shorter the detection distance would be (Table 7). The best relative position for the RFID detection was where the card was parallel to the antenna. The antennas fixed on the sprayer should be parallel to the tractor frame (Fig. 3), while the cards fixed on the rows should be parallel to the orchard/vineyard rows.

\section{RFID detection test at different moving speeds}

The results of the RFID detection tests at different moving speeds are presented in Table 8. The data showed that when the centers of the antennas and the cards were at the same height, the RFID reader could read all ten cards if the speed was not more than $1.75 \mathrm{~m} / \mathrm{s}$.

\section{Field test for the developed spray monitoring system with two RFID antennas}

In the system simulation test, each RFID card was detected. The test results showed that the system could distinguish the travel direction of the sprayer, identify sprayer location in

Table 5 Results of RFID detection distances while the reader was at different Power RFLevels

\begin{tabular}{llllll}
\hline Power RFLevel $(\mathrm{dBm})$ & \multicolumn{5}{l}{ RFID detection distance $(\mathrm{m})$} \\
\cline { 2 - 5 } & Read 1 & Read 2 & Read 3 & Average & Standard deviation \\
\hline 17 & 1.07 & 1.07 & 1.09 & 1.07 & 0.01 \\
20 & 1.59 & 1.60 & 1.65 & 1.61 & 0.03 \\
23 & 3.18 & 3.20 & 3.33 & 3.23 & 0.08 \\
26 & 4.47 & 4.50 & 4.55 & 4.50 & 0.04 \\
29 & 5.44 & 5.40 & 5.50 & 5.44 & 0.05 \\
\hline
\end{tabular}


Table 6 Results of RFID detection distances at different card angles with the Power RFLevel of $23 \mathrm{dBm}$

\begin{tabular}{llllll}
\hline Card angle $\left({ }^{\circ}\right)$ & \multicolumn{5}{l}{ RFID detection distance $(\mathrm{m})$} \\
\cline { 2 - 6 } & Read 1 & Read 2 & Read 3 & Average & Standard deviation \\
\hline 0 & 3.18 & 3.20 & 3.33 & 3.23 & 0.08 \\
20 & 2.48 & 2.50 & 2.45 & 2.48 & 0.03 \\
40 & 2.44 & 2.44 & 2.15 & 2.34 & 0.17 \\
60 & 1.65 & 1.63 & 1.61 & 1.63 & 0.02 \\
80 & 1.18 & 1.18 & 1.24 & 1.20 & 0.04 \\
\hline
\end{tabular}

Table 7 Results of RFID detection distance at different antenna angles with the Power RFLevel of $23 \mathrm{dBm}$

\begin{tabular}{llllll}
\hline Antenna angle $\left(^{\circ}\right)$ & \multicolumn{5}{l}{ RFID detection distance $(\mathrm{m})$} \\
\cline { 2 - 6 } & Read 1 & Read 2 & Read 3 & Average & Standard deviation \\
\hline 0 & 3.18 & 3.20 & 3.33 & 3.23 & 0.08 \\
15 & 2.26 & 2.41 & 2.30 & 2.32 & 0.08 \\
30 & 1.47 & 1.55 & 1.54 & 1.52 & 0.04 \\
45 & 0.93 & 0.91 & 0.86 & 0.90 & 0.03 \\
60 & 0.44 & 0.43 & 0.46 & 0.44 & 0.01 \\
75 & 0.37 & 0.38 & 0.41 & 0.39 & 0.02 \\
\hline
\end{tabular}

Table 8 Test results of RFID detection at different moving speeds with the Power RFLevel of $29 \mathrm{dBm}$

\begin{tabular}{lll}
\hline Antenna & Speed $(\mathrm{m} / \mathrm{s})$ & Number of cards read \\
\hline Right antenna & 0.45 & 10 \\
Right antenna & 0.91 & 10 \\
Right antenna & 1.56 & 10 \\
Left antenna & 0.47 & 10 \\
Left antenna & 0.93 & 10 \\
Left antenna & 1.75 & 10 \\
\hline
\end{tabular}

the field, record flow rate information, calculate sprayed volume, and show all the above information on a computer screen correctly in real time.

The field test results showed that the reader registered most of the cards, but missed some during the tests (Table 9 Test 1-3). After each card and antenna were adjusted at the same height, the reader captured all of the cards (Table 9 Test 4). The cards missing could be because of tractor movement caused by rough field terrain which could have created significantly unequal height between the antennas and the cards. When the reader recorded all the cards, the computer software worked very well. The sprayer locations and moving direction were identified correctly. The real-time flow rate, the volume sprayed on each side of the row and the total volume sprayed in the field were calculated and displayed. 
Table 9 Results of the RFID detection system test in the field with the Power RFLevel of $29 \mathrm{dBm}$

\begin{tabular}{lllcc}
\hline Test & Speed $(\mathrm{m} / \mathrm{s})$ & Total number of cards & Number of cards read & Percent $(\%)$ \\
\hline Test 1 & 0.9 & 12 & 9 & 75 \\
Test 2 & 0.9 & 12 & 11 & 92 \\
Test 3 & 0.9 & 12 & 10 & 83 \\
Test 4 & 0.9 & 12 & 12 & 100 \\
\hline
\end{tabular}

Table 10 Test results of the new RFID card reading in the field with the Power RFLevel of $29 \mathrm{dBm}$

\begin{tabular}{|c|c|c|c|c|c|c|c|c|c|c|c|c|}
\hline \multirow{2}{*}{$\begin{array}{l}\text { Speed } \\
(\mathrm{m} / \mathrm{s})\end{array}$} & \multirow[t]{2}{*}{ Antenna } & \multicolumn{10}{|c|}{ Reading number of RFID card } & \multirow{2}{*}{$\begin{array}{l}\text { Average } \\
\text { reading } \\
\text { number }\end{array}$} \\
\hline & & 1 & 2 & 3 & 4 & 5 & 6 & 7 & 8 & 9 & 10 & \\
\hline \multirow[t]{3}{*}{0.6} & Front & 2 & 2 & 2 & 2 & 5 & 3 & 3 & 2 & 3 & 4 & 2.8 \\
\hline & Back & 3 & 4 & 3 & 4 & 5 & 4 & 3 & 3 & 3 & 3 & 3.5 \\
\hline & Total & 5 & 6 & 5 & 6 & 10 & 7 & 6 & 5 & 6 & 7 & 6.3 \\
\hline \multirow[t]{3}{*}{1.1} & Front & 1 & 2 & 2 & 2 & 1 & 2 & 1 & 2 & 2 & 2 & 1.7 \\
\hline & Back & 2 & 2 & 2 & 3 & 3 & 3 & 2 & 2 & 1 & 2 & 2.2 \\
\hline & Total & 3 & 4 & 4 & 5 & 4 & 5 & 3 & 4 & 3 & 4 & 3.9 \\
\hline \multirow[t]{3}{*}{1.8} & Front & 1 & 1 & 1 & 0 & 1 & 1 & 1 & 1 & 1 & 1 & 0.9 \\
\hline & Back & 2 & 1 & 1 & 2 & 2 & 2 & 1 & 1 & 1 & 2 & 1.5 \\
\hline & Total & 3 & 2 & 2 & 2 & 3 & 3 & 2 & 2 & 2 & 3 & 2.4 \\
\hline
\end{tabular}

\section{Field test for the improved spray monitoring system with four RFID antennas}

Based on the field test, the best angle $\theta$ of the two antennas was determined to be $125^{\circ}$, and the maximum scope length from point "B" to "C" (Fig. 15) was $3.86 \mathrm{~m}$. If the sprayer moves at $1.8 \mathrm{~m} / \mathrm{s}$, the card could be read 3.18 times on average according to the calculation. In the same working conditions, the more times the system can read the RFID card, the less likely the reader was to miss the card.

In the field test, this improved system could successfully capture all the cards at random heights between the centers of the two antennas on the same side, which were $0.26 \mathrm{~m}$ apart. The test results of the improved RFID system are presented in Table 10.

Comparing the two monitoring systems, the system with two antennas was simple, inexpensive and a little easier to setup on a tractor, but it required the card and the antenna to be at the same height when the tractor was passing by. The system with four antennas only required the cards to be put in the band with a width of $0.26 \mathrm{~m}$ between the centers of the two antennas to make them operable.

\section{Conclusions}

(1) An RFID solution for identification of orchard and vineyard sprayer movement was put forward, which could identify sprayer location and its direction of travel even when the GNSS guiding system failed due to unstable satellite signals in a field with tall and large tree/plant canopies. 
(2) A spray monitoring and guiding system was designed and developed based on the RFID solution, which not only could automatically identify the movement of the sprayer, but also could read and record the real-time flow rates from the flow meters on both sides of the sprayer, calculate the volume of the pesticide sprayed, and display the result on the in-cab computer screen for the sprayer operator in real time for assisting tractor driving.

(3) For the monitoring and guiding system with one antenna on each side, the best relative position was found by placing the card parallel to the antenna. For the improved system with two antennas on each side, the best angle of the two antennas was $125^{\circ}$. The field test results showed that the improved system worked well when the speed of the sprayer was less than $1.8 \mathrm{~m} / \mathrm{s}$.

(4) In order to make sure each RFID card was captured, the system with two antennas critically required the cards and the antennas to be at the same height when the tractor was passing by. The improved system with four antennas, only required the cards to be put in the band with a width of $0.26 \mathrm{~m}$ between the centers of the two antennas to make them operable.

(5) The monitoring and guiding system could be used in an orchard or a vineyard with a constant row width. The RFID solution could be used in a similar situation for location identification in an open field or indoor area.

Acknowledgements This work was funded by the New York Apple Research and Development Fund, the New York Wine and Grape Foundation, the China Scholarship Council, the Project 31201128 supported by NSFC and the "Young Faculty Study Abroad Program" of Northwest A\&F University Scholarship Fund. We are grateful to Bill Larzelere and Jordi Llorens from Cornell University for their help during field trials. We also thank Peter Deisenroth from Bristol ID Technologies and Rick Howitt from Agrinetix LLC. This work was conducted while the first author was at Cornell University.

Author contributions Changyuan Zhai and Andrew Landers conceived and designed the study. Changyuan Zhai developed the spray monitoring system and performed the experiments. Changyuan Zhai wrote Sects. 2-4 of the manuscript, while Bo Zhang wrote Sect. "Introduction". All authors read and approved the manuscript.

\section{Compliance with ethical standards}

Conflicts of interest The authors declare that they have no conflict of interest.

Open Access This article is distributed under the terms of the Creative Commons Attribution 4.0 International License (http://creativecommons.org/licenses/by/4.0/), which permits unrestricted use, distribution, and reproduction in any medium, provided you give appropriate credit to the original author(s) and the source, provide a link to the Creative Commons license, and indicate if changes were made.

\section{References}

Ampatzidis, Y. G., Vougioukas, S. G., Bochtis, D. D., \& Tsatsarelis, C. A. (2009). A yield mapping system for hand-harvested fruits based on RFID and GPS location technologies: Field testing. Precision Agriculture, 10, 63-72. doi:10.1007/s11119-008-9095-8.

Arduino - Home. (n.d.). Retrieved July 24, 2017, from https://www.arduino.cc/

Aung, M. M., \& Chang, Y. S. (2014). Traceability in a food supply chain: Safety and quality perspectives. Food Control, 39, 172-184. doi:10.1016/j.foodcont.2013.11.007.

Awad, A. I. (2016). From classical methods to animal biometrics: A review on cattle identification and tracking. Computers and Electronics in Agriculture, 123, 423-435. doi:10.1016/j.compag.2016.03.014.

Fan, H., Wu, Q., Lin, Y., \& Zhang, J. (2013). A split-path schema-based RFID data storage model in supply chain management. Sensors (Basel, Switzerland), 13(5), 5757-5776. doi:10.3390/s130505757. 
Gil, E., Llorens, J., Llop, J., Fàbregas, X., \& Gallart, M. (2013). Use of a terrestrial LIDAR sensor for drift detection in vineyard spraying. Sensors (Basel, Switzerland), 13(1), 516-534. doi:10.3390/ s130100516.

Hancke, G. P. (2011). Design of a secure distance-bounding channel for RFID. Journal of Network and Computer Applications, 34(3), 877-887. doi:10.1016/j.jnca.2010.04.014.

Jeon, H. Y., \& Zhu, H. (2012). Development of variable-rate sprayer for nursery liner applications. Transactions of the ASABE, 55(1), 303-312.

Juraske, R., Fantke, P., Ramírez, A. C. R., \& González, A. (2012). Pesticide residue dynamics in passion fruits: Comparing field trial and modelling results. Chemosphere, 89(7), 850-855. doi:10.1016/j. chemosphere.2012.05.007.

Ko, C.-H. (2010). RFID 3D location sensing algorithms. Automation in Construction, 19(5), 588-595. doi:10.1016/j.autcon.2010.02.003.

Landers, A., \& Larzelere, B. (2012). The development of a spray monitoring system as an aid to orchard management and traceability. New York Fruit Quarterly, 20(4), 21-24.

Lee, W. S., Alchanatis, V., Yang, C., Hirafuji, M., Moshou, D., \& Li, C. (2010). Sensing technologies for precision specialty crop production. Computers and Electronics in Agriculture, 74(1), 2-33. doi:10. 1016/j.compag.2010.08.005.

Li, L., Li, H., He, X., \& Andreas, H. (2012). Development and experiment of automatic detection device for infrared target. Transactions of the CSAE, 28(12), 159-163.

Peets, S., Gasparin, C. P., Blackburn, D. W. K., \& Godwin, R. J. (2009). RFID tags for identifying and verifying agrochemicals in food traceability systems. Precision Agriculture, 10, 382-394. doi:10.1007/ s11119-009-9106-4.

Pérez-Ruiz, M., Agüera, J., Gil, J. A., \& Slaughter, D. C. (2011). Optimization of agrochemical application in olive groves based on positioning sensor. Precision Agriculture, 12, 564-575. doi:10.1007/s11119010-9200-7.

Pizzuti, T., Mirabelli, G., Sanz-Bobi, M. A., \& Goméz-Gonzaléz, F. (2014). Food track \& trace ontology for helping the food traceability control. Journal of Food Engineering, 120, 17-30. doi:10.1016/j. jfoodeng.2013.07.017.

Pontikakos, C. M., Tsiligiridis, T. A., Yialouris, C. P., \& Kontodimas, D. C. (2012). Pest management control of olive fruit fly (Bactrocera oleae) based on a location-aware agro-environmental system. Computers and Electronics in Agriculture, 87, 39-50. doi:10.1016/j.compag.2012.05.001.

Poulsen, M. E., Wenneker, M., Withagen, J., \& Christensen, H. B. (2012). Pesticide residues in individual versus composite samples of apples after fine or coarse spray quality application. Crop Protection, 35 , 5-14. doi:10.1016/j.cropro.2011.12.013.

Reyes, J. F., Correa, C., Esquivel, W., \& Ortega, R. (2012). Development and field testing of a data acquisition system to assess the quality of spraying in fruit orchards. Computers and Electronics in Agriculture, 84, 62-67. doi:10.1016/j.compag.2012.02.018.

Ruiz-garcia, L., \& Lunadei, L. (2011). The role of RFID in agriculture: Applications, limitations and challenges. Computers and Electronics in Agriculture, 79(1), 42-50. doi:10.1016/j.compag.2011.08. 010 .

Schwägele, F. (2005). Traceability from a European perspective. Meat Science, 71(1), 164-173. doi:10. 1016/j.meatsci.2005.03.002.

Souza Monteiro, D. M., \& Caswell, J. A. (2009). Traceability adoption at the farm level: An empirical analysis of the Portuguese pear industry. Food Policy, 34(1), 94-101. doi:10.1016/j.foodpol.2008.07. 003.

Thakur, M., \& Forås, E. (2015). EPCIS based online temperature monitoring and traceability in a cold meat chain. Computers and Electronics in Agriculture, 117, 22-30. doi:10.1016/j.compag.2015.07.006.

Vales-Alonso, J., Bueno-Delgado, M. V., Egea-López, E., Alcaraz, J. J., \& Pérez-Mañogil, J. M. (2011). On the optimal identification of tag sets in time-constrained RFID configurations. Sensors (Basel, Switzerland), 11(3), 2946-2960. doi:10.3390/s110302946.

Wilson, J. S., \& Otsuki, T. (2004). To spray or not to spray: Pesticides, banana exports, and food safety. Food Policy, 29(2), 131-146. doi:10.1016/j.foodpol.2004.02.003. 